\title{
Masonry buildings strengthened with textile-fiber composite (TRC) layers and fiber-reinforced cementitious (FRC) layers
}

\author{
Teddy Boen ${ }^{1 *}$, Hiroshi Imai $^{2}$, Lenny ${ }^{1}$, and Sarah E. Suryanto ${ }^{1}$ \\ ${ }^{1}$ Structural Engineer, CSI Indonesia \\ ${ }^{2}$ Professor Institute of Technologists, Japan
}

\begin{abstract}
In June 2015, the authors published a paper titled "Brief Report of Shaking Table Test on Masonry Building Strengthened with Ferrocement Layers" [1]. The authors suggested in that paper to replace the traditional way of constructing masonry houses using the so called practical columns and beams (herein after called traditional masonry houses) with bandaging using ferrocement layers on both sides of the walls as skin facings and brick wall as core. Since then, many masonry houses bandaged with ferrocement layers are built in Indonesia. Apart from constructing new earthquake resistant houses, ferrocement bandaging is also used for retrofitting existing as well as damaged houses after earthquakes. In the past decades, continuous fiber mesh was introduced to replace the steel wire mesh in a cementitious matrix. Since the early 2000, textile-based composites were used in the field of strengthening and seismic retrofitting of masonry as well as concrete structures. Originally these new "textile fiber composite" materials are called "Textile Reinforced Concrete" (TRC) in Europe. However, in the USA, the term used is "Fiber Reinforced Cementitious Matrix systems" (FRCM). Extensive research on FRCM / TRC were conducted. A wide variety of publications on the subject matter are now available worldwide. Apart from TRC, many technical studies are published addressing fiber reinforced cement and concrete composite. The term "Fiber Reinforced Cementitious" (FRC) is used and defined as concrete and/or cementitious matrix with suitable discontinuous fibers added to it for the purposes of achieving a desired level of performance in a particular property, such as modulus elasticity, tensile strength, and ductility [2]. Lately, the use of discontinuous fibers as reinforcement for concrete and cementitious matrix FRC are introduced by many practitioners and civil engineers. Adding fibers in concrete / cementitious matrix mixer simply like adding sand or admixtures, to create a homogenous, isotropic, strong, tough, durable, and moldable structural materials [2]. In this paper the authors used the terms of TRC and FRC as defined by Naaman [2,3], namely TRC for fiber-cement with fiber-mesh and FRC for fiber-cement with discontinuous fiber. This paper provides a simplified global analysis of the overall structure strengthened with FRCM / TRC as well as strengthened with FRC.
\end{abstract}

\section{Introduction}

In 2012 the authors did a global dynamic analysis of a masonry house strengthened by wrapping the walls with ferrocement layers. Subsequently a full-scale shaking table test was conducted in Tsukuba Japan for the masonry house [4] and the result of the analysis is in line with the performance of the masonry house based on the shaking table test. Subsequently in 2014, the authors did a structural analysis for the similar masonry house bandaged with ferrocement layers instead of wrapping. In June 2014, a full-scale shaking table test was conducted again in Tsukuba for the masonry house bandaged with ferrocement layers. Once again, the results of the fullscale shaking table test did match with the results of the dynamic analysis of that masonry house [1].
Based on published research, papers, and books [2, 3, $5,6,7]$, in terms of intrinsic mechanical properties, such as tensile strength, shear, strength, equivalent elastic bending stress, fracture toughness, fracture energy, ferrocement is suitable for strengthening masonry houses for earthquake resistance. Ferrocement layers of $2 \mathrm{~cm}$ applied on both sides of masonry walls are sufficient to prevent collapse when shaken by strong earthquakes (JMA Kobe $100 \%$ 0.876g).

Advantages of ferrocement as a construction material, among others

Advantages of ferrocement as a construction material, among others:

- ferrocement is feasible in the context of social, cultural, economical, political, and technical constraints typical in developing countries.

\footnotetext{
* Corresponding author: tedboen@cbn.net.id
} 
- ferrocement require a low level of technology and can be done by local masons with local tools / construction equipment, and local tradesmen's skills

- the construction period is relatively short so that the building can be occupied asap.

- ferrocement is suitable for self-help construction for housing; the methodology can be carried out by homeowners with minimal financial and technical assistance, and in case of retrofitting, do not require extensive reconstruction or modification of the existing building.

In spite of the advantages stated above, the constructions of ferrocement shall be strictly supervised because proper installation and adequate curing conditions for the mortar matrixes are crucial for the effectiveness of the work. Wrongly constructed ferrocement reduce the performance of ferrocement. Building earthquake resistant masonry houses bandaged with ferrocement layers have already been implemented in Indonesia as can be seen in Fig. 1. More pictures can be seen in www.teddyboen.com.
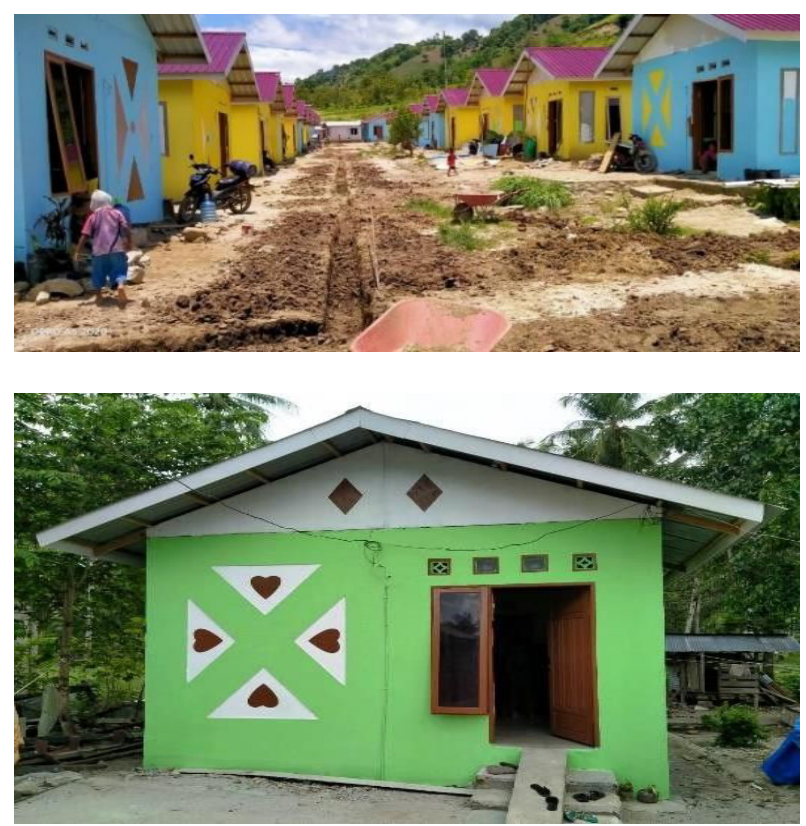

Fig. 1. Earthquake resistant masonry houses bandaged with ferrocement layers in Indonesia

Since 1980's, the use of high-performance textile fiber has gained increased attention in structural engineering applications. Textile fibers are being used instead of steel wire mesh. Currently, many countries produce textile fiber meshes with geometric and mechanical properties suitable for use in cement-based matrixes. Fiber textile meshes offer better corrosion resistance than ordinary steel wire mesh and are produced in practically any length and thus can be shaped to requirements. However, unlike wire mesh that has similar dimension and material properties, there are many different dimensions and properties of fibers around the world based on the manufactures.

The main common characteristics of Textile Reinforced Concrete (TRC) is that the ultimate tensile strain of the matrix is much smaller than the yield of reinforcement [6]. Therefore, the matrix will crack and the resistance to full separation is entirely mobilized by the reinforcement bridging the cracked surface. This does not matter for earthquake resistant masonry houses because the main aim of using ferrocement or fiber textile cement for building earthquake resistant as well as strengthening of existing masonry houses is to prevent collapse, therefore, cracks when shaken by earthquakes can be tolerated. However, the use of TRC requires careful placement and needs strict supervision. It also leads to an anisotropic building material which is not understandable for the average layman $[2,8]$.

For Fiber Reinforced Cementitious (FRC), there are two types of discontinuous fiber that can be used in matrix / concrete composite, i.e. natural fiber and synthetic fiber. Natural fiber reinforced concrete consists of smalldiameter discontinuous, discrete natural fibers of different origin randomly distributed in a cementitious matrix [9]. It includes coconut fiber, sisal fiber, sugarcane bagasse fiber, bamboo fiber, palm fiber, jute fiber, wood fiber and some vegetable fibers. Meanwhile many varieties of synthetic fiber available with different properties that qualify as low strength, high strength or ultra-high strength, such as PVA (Poly Vinyl Alcohol), PP (PolyPropylene), nylon which have low tensile strength and low modulus elasticity; steel, E-glass, basalt, asbestos which have high tensile strength and high modulus elasticity; carbon, poly p-phenylene benzobisoxazole (PBO), spectra which have higher tensile strength, higher modulus elasticity and lighter with specific gravity lower than one.

The low-end synthetic fibers, such as Polyvinyl Alcohol (PVA), Polypropylene (PP), nylon, are usually used in non-structural applications, particularly to control plastic shrinkage cracking of concrete at early age and the fibers contribution to the mechanical properties of the composite is ignored [2]. However, with an appropriate volume fraction of fibers, it also can be used for structural applications. The high-end synthetic fibers, such as carbon, PBO, spectra, have had limited use since their cost is among the highest as well. For those reasons above, in this paper, the author decided to use the middle level of fiber such as steel, E-glass, basalt, PVA and PP in mortar mix. The addition of a small amount of fiber in mortar / concrete mix will increase the toughness, energy absorption capacity, and ductility of the mixture [2].

Composite properties are based on volume fraction of fiber, therefore, the cost based on equal performance is more economical when using TRC/FRC. At the moment, a lot of research have been conducted in various countries, in the USA, in Europe, in Japan, etc. and the results are readily available. The authors plan to introduce ferrocement using textile fiber meshes (TRC) or discontinuous fiber (FRC) for constructing earthquake resistant masonry houses as well as retrofitting of existing traditional masonry houses in Indonesia. Unfortunately, research with regards to TRC/FRC in Indonesia is not widely available. Thus, the authors utilize available research works and material from books related to ferrocement and TRC/FRC to introduce constructing earthquake resistant masonry houses bandaged with fiber cement layers in Indonesia. The authors have no intention 
re-inventing the wheel by duplicating similar research already available in publications but use those researches to get the benefit for the common people. The method can also be used to strengthen existing masonry houses for earthquake resistance. So far, in ACI549.6R-20 [6] and other research papers and books, ferrocement is proven suitable for strengthening system for existing individual masonry walls, subject to in-plane and out-of-plane loads resulting from wind and earthquakes [6]. The TRC strengthening system for individual walls should evaluate the effect of strengthening as on the overall structures [6].

Similar to the strengthening system with ferrocement (using steel wire mesh) for masonry houses in Indonesia which was introduced in 2006, the author also perform a global analysis of the overall structure strengthened with TRC/FRC bandaging. For the purpose, a structural dynamic analysis similar to that performed in 2014 for a masonry house bandaged with ferrocement layers is conducted. Using textile fiber meshes (TRC) instead of wire mesh and using FRC, the authors rely on material properties and fiber types from credible research results published in scientific journals.

If the dynamic analyses show good results, the authors are of the opinion that TRC and FRC can be applied. Another method to verify the results is a full-scale shaking table test which hopefully can be conducted in the near future..

\section{Structure Model}

The model for analysis is taken from previous shaking table test [1], i.e. masonry structure strengthened by providing bandaging using $2 \mathrm{~cm}$ fiber-cement layers on both sides of the walls, acting as sandwich structures. The layout of house can be seen in Fig. 2.

The model consists of four walls with size $3.6 \mathrm{~m} \mathrm{x}$ $2.6 \mathrm{~m}$ with four simple roof trusses and galvanized ironsheets roofing. The gable walls located at West and East elevations which are perpendicular to the direction of the shaking.

The fiber-cement layers are analyzed as TRC as well as FRC. Fig. 3 shows the schematic drawings for house strengthened using TRC. The fiber-mesh is installed in the middle of fiber-cement layers. Fig. 4 shows the schematic drawings for house strengthened using FRC. The discontinuous fiber is mixed together with mortar.

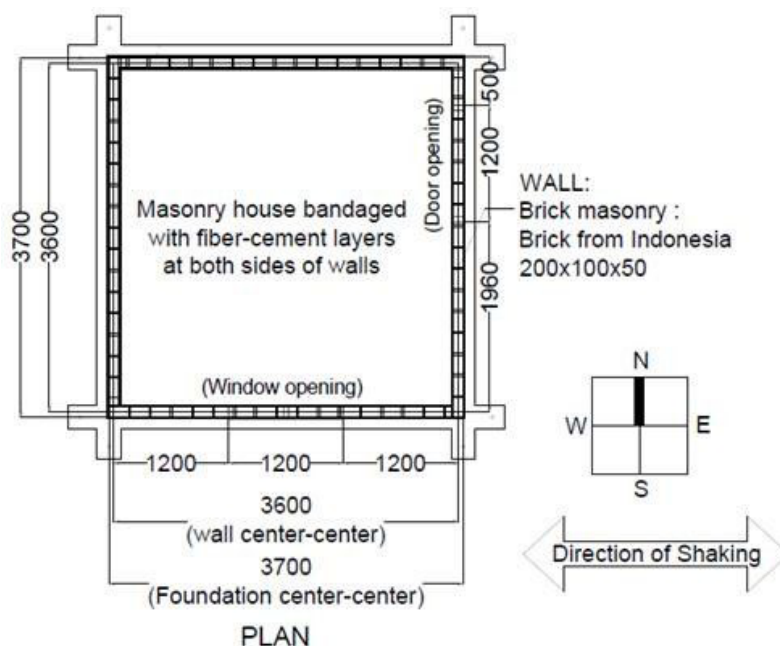

Fig. 2 Layout of house strengthened with fiber-cement la

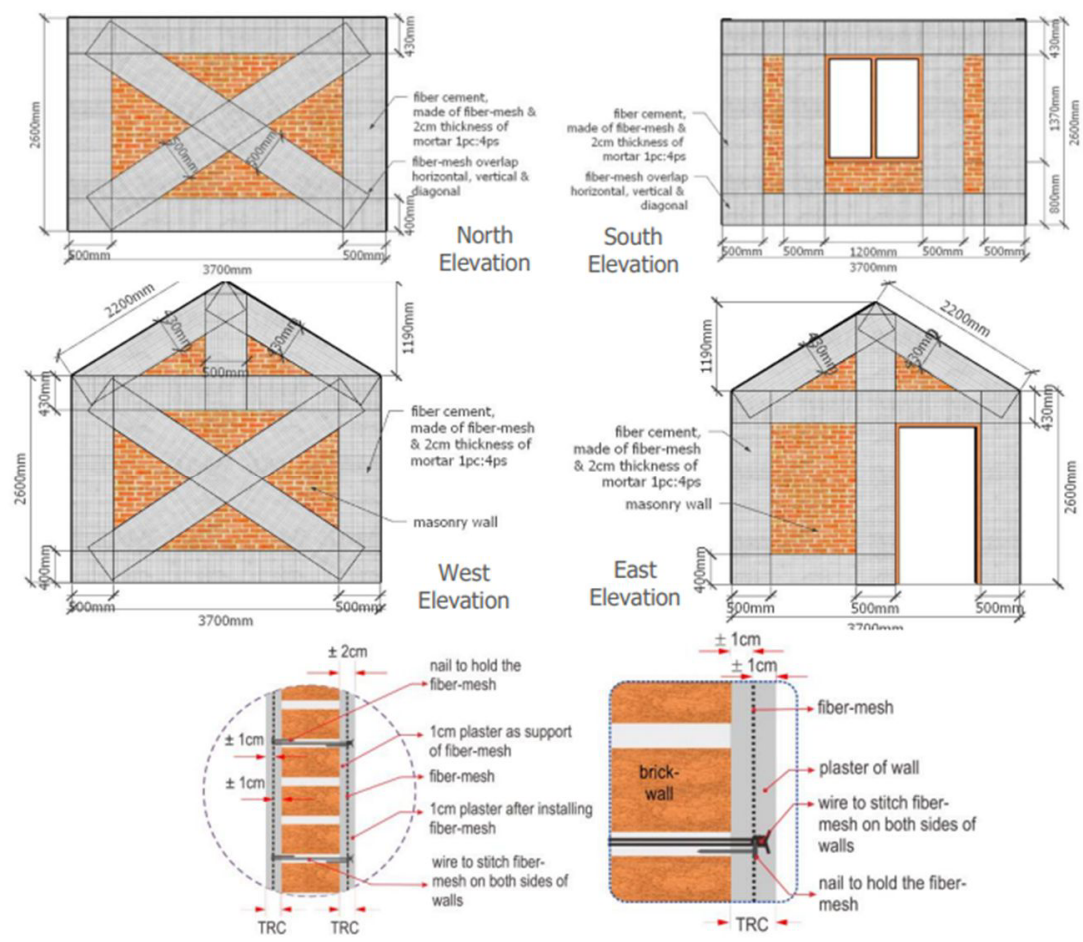

Fig 3. Schematic drawings of house strengthened with fiber-cement layers using fiber mesh (TRC) 

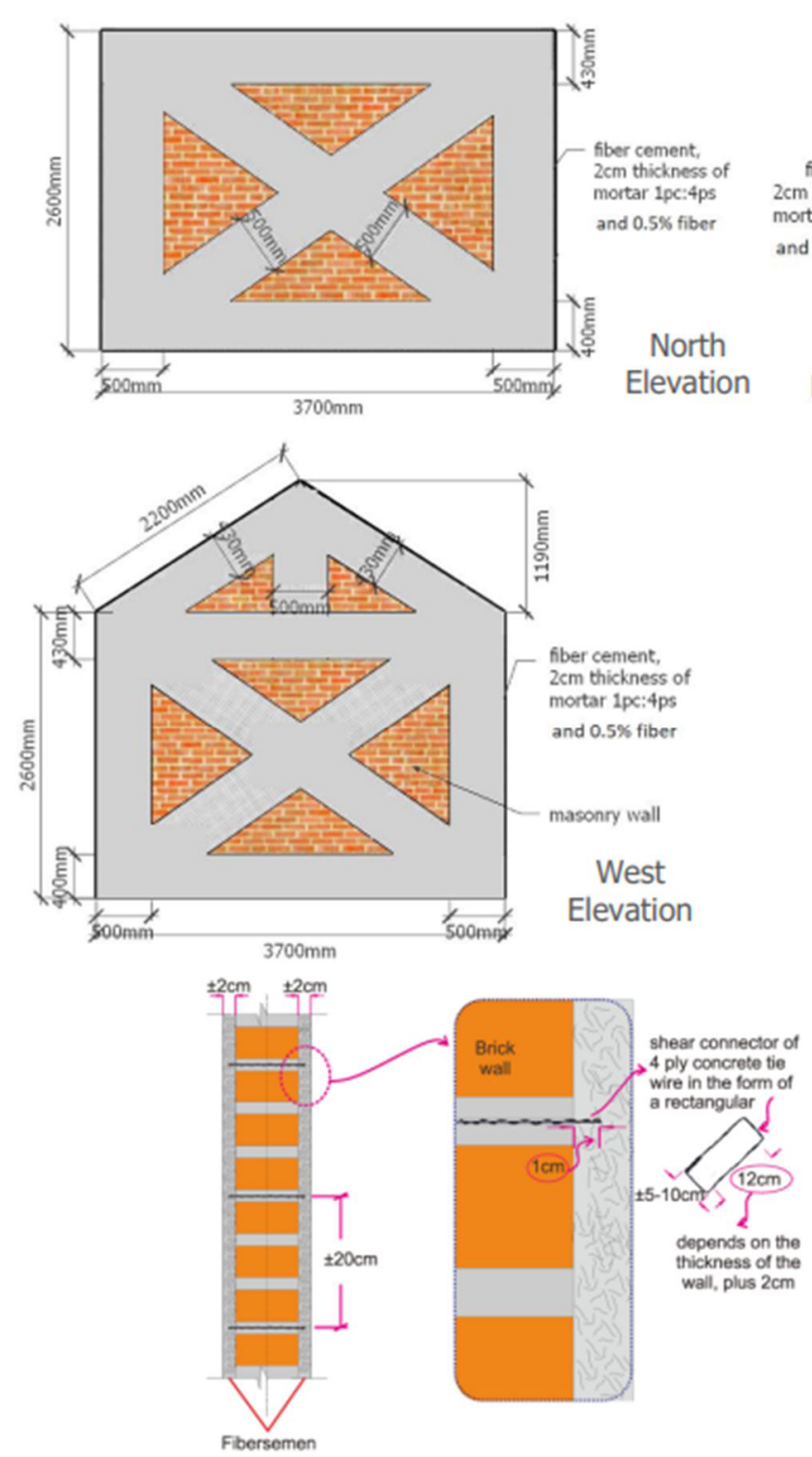
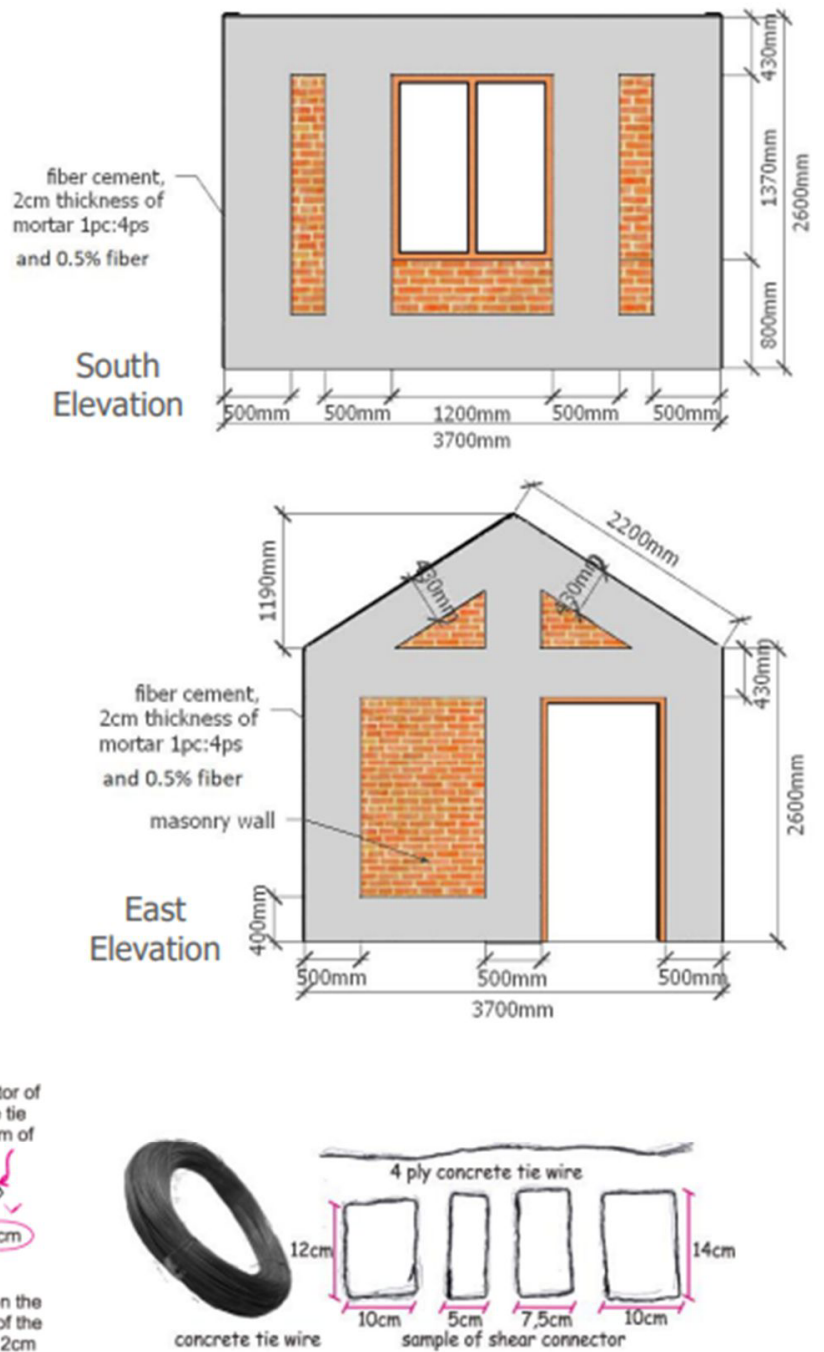

Fig. 4. Schematic drawings of house strengthened with fiber-cement layers using discontinuous fiber (FRC)

\section{Material Properties}

Material properties of brick-walls used for the analysis are taken from previous shaking table test in Tsukuba, 2014 [1]. The modulus elasticity of brick-walls is $5885 \mathrm{kgf} / \mathrm{cm} 2$ with adhesion tensile strength of mortar (1pc:6sand) used for the brick-walls $3.5 \mathrm{kgf} / \mathrm{cm} 2$. The compressive strength of mortar (1pc:4sand) for fiber-cement layer is $275.8 \mathrm{kgf} / \mathrm{cm} 2$, and the modulus elasticity is $211,950 \mathrm{kgf} / \mathrm{cm} 2$.

\subsection{Fiber-cement using TRC}

Since TRC is relatively new in Indonesia, the analysis is done for five different types of fibers, i.e. aragrid-mesh, basalt, carbon, glass, and PBO. The material properties for those fibers are taken from tests previously conducted $[3,6,7]$.
Table 1 below shows the material properties for 5 types of fibers that are used in the analysis, i.e. aragrid, basalt, carbon, glass, and PBO, as can be seen in Fig. 5. For this analysis purpose, the TRC only uses one layer of fiber because the masonry walls with TRC layers on both sides of the walls are acting as sandwich construction. Therefore, the TRC layer is not acting as a load-bearing single layer such as usually used for cement boards, corrugated cement sheets,pipes, cladding, shells, roofs, domes, water tanks, water channels, boats, etc. [5].

\subsection{Fiber-cement using FRC}

For FRC, there are 5 types of fibers used in the analysis, i.e. E-glass, basalt, steel, PVA, and PP. Cement bags and rice bags are also made from PP Woven Fiber (see Fig. 6). Therefore, those materials can also be used for low-cost housing program and not become waste. The tensile strength and modulus elasticity are taken from publications $[2,10]$. Table 2 shows the material properties for 5 types 
of discontinuous fibers that are used in the analysis. For Eglass, basalt and steel, the volume fraction is $0.5 \%$; however, for PVA and PP which have low modulus elasticity, the volume fraction is $0.75 \%-1 \%$. The aim is to obtain the strain hardening behavior for FRC composite in tension as can be seen in Fig. 7 where maximum postcracking stress $\sigma p c$ should be greater than the tensile stress at first cracking of the matrix $\sigma \mathrm{cc}$. Tensile stress at first cracking of matrix, $\sigma c c$ and maximum post-cracking stress, opc can be calculated as mentioned in Chapter 9 Modeling Tension, Fiber Reinforced Cement and Concrete
Composite [2]. The tensile strength of the composite, $\sigma c c$, is primarily influenced by the tensile strength of the matrix, while the post-cracking strength, $\sigma p c$, is mainly dependent on the fiber reinforcing parameters and the bond at the fiber-matrix interface $[2,11,12]$. When the tensile stresses of fiber-cement are greater than $\sigma c c$, multiple cracks start to develop at the mortar. Failure of FRC occurs when either the matrix fiber bonding strength is exceeded, or when the fiber breaks $[11,12]$, meaning when the tensile stress of FRC exceeds the maximum post-cracking stress, бpc.

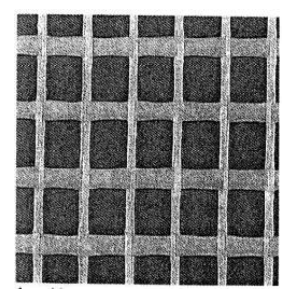

Aragrid

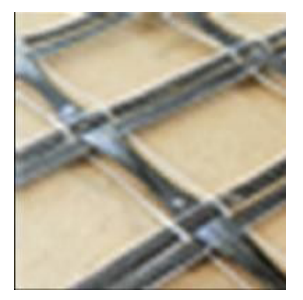

Basalt

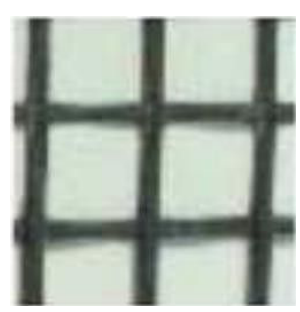

Carbon

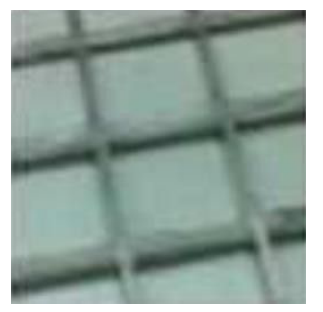

Glass

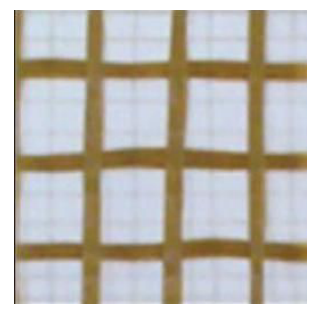

PBO

Fig. 5. Fiber-mesh used for the analysis $[3,6,7]$

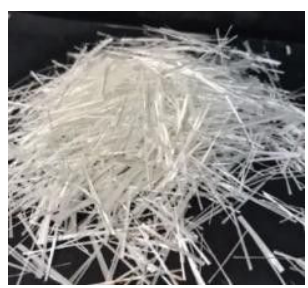

Glass fiber*

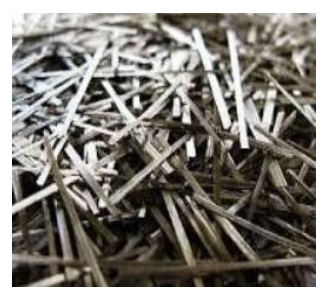

Basalt fiber $^{* *}$

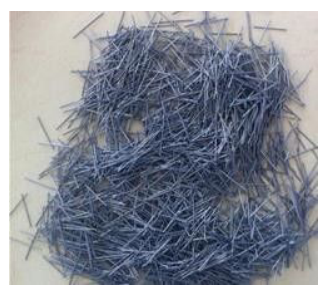

Steel fiber ${ }^{* * *}$

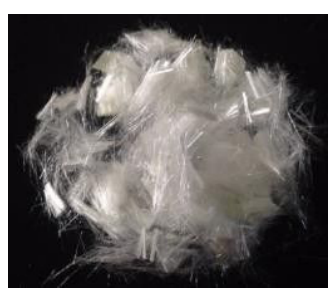

PVA fiber ${ }^{* * * *}$

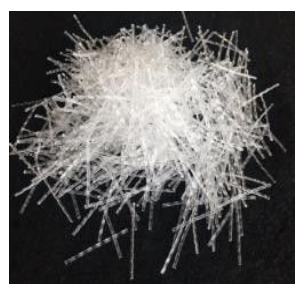

PP fiber

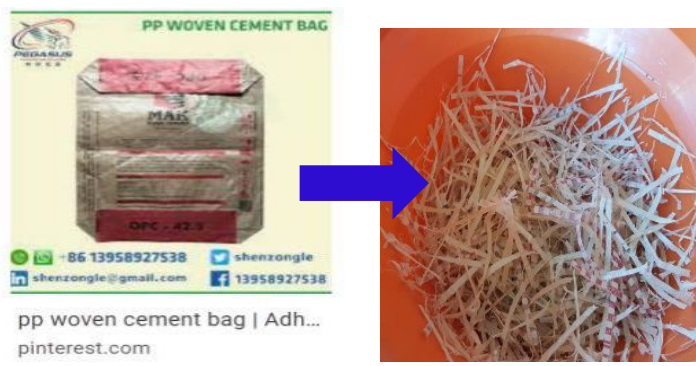

PP Woven Cement Bags

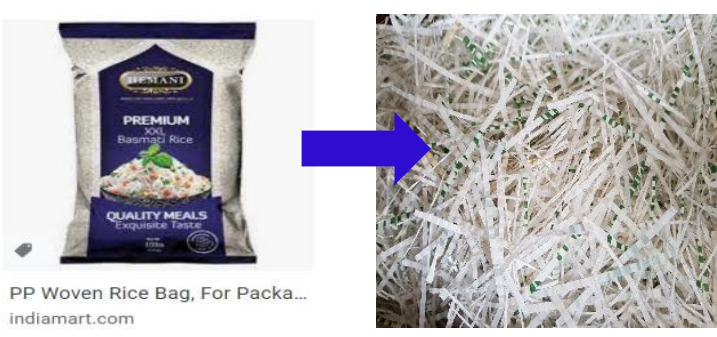

PP Woven Rice bags

Fig. 6. The discontinuous fiber used for the analysis

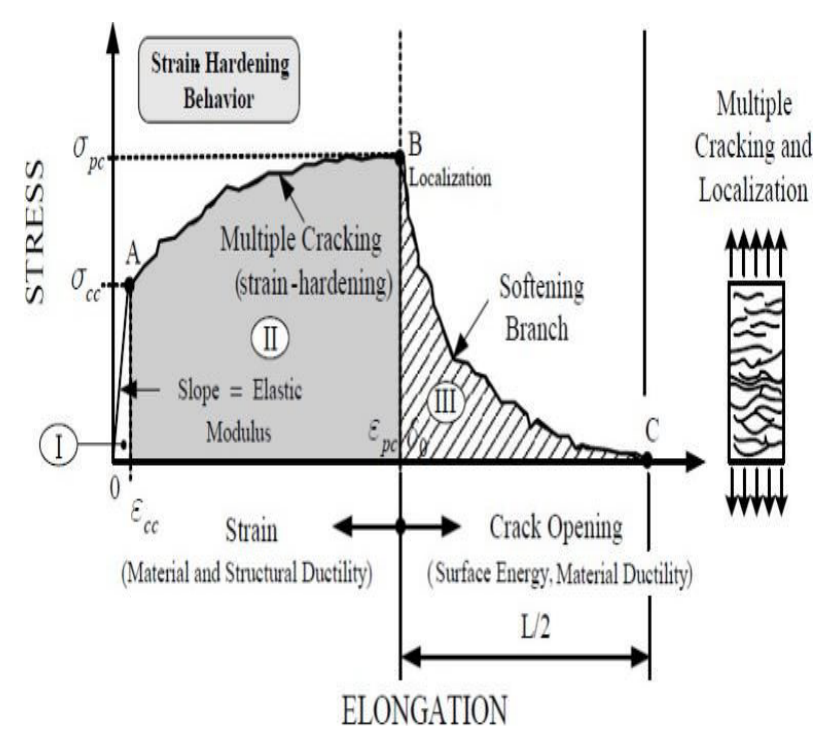

Fig. 7 Strain hardening behavior for FRC composites in tension [13] 
Table 1 Material properties of fiber mesh for TRC $[3,6,7]$

\begin{tabular}{|l|c|r|r|r|r|r|}
\hline Fiber Mesh: & Units & \multicolumn{1}{c|}{ Basalt } & Carbon & \multicolumn{1}{c|}{ Glass } & \multicolumn{1}{c|}{ Aragrid } & \multicolumn{1}{c|}{ PBO } \\
\hline Grid spacing of fiber mesh & $\mathrm{mm}$ & $25 \times 25$ & $20 \times 20$ & $15 \times 15$ & $10.5 \times 10.5$ & $15 \times 15$ \\
\hline Unit weight, $W_{r}$ & $\mathrm{~g} / \mathrm{m}^{2}$ & 220 & 170 & 218 & 154 & 44 \\
\hline Density, $Y_{r}$ & $\mathrm{~g} / \mathrm{cm}^{3}$ & 2.6 & 1.8 & 2.6 & 1.45 & 1.56 \\
\hline Tensile strength, $f_{f u}$ & $\mathrm{MPa}$ & 2,438 & 1,876 & 1,700 & 2,030 & 3,356 \\
\hline Modulus elasticity, $E_{f}$ & $\mathrm{GPa}$ & 108 & 219 & 72 & 45 & 192 \\
\hline Fiber-cement: & & & & & & \\
\hline Volume fraction of fiber, $V_{f}$ & $\%$ & 0.42 & 0.47 & 0.42 & 0.53 & 0.14 \\
\hline Volume fraction of mortar, $V_{m}$ & $\%$ & 99.58 & 99.53 & 99.58 & 99.47 & 99.86 \\
\hline Modulus elasticity of fiber-cement, $E_{c}$ & $\mathrm{kgf} / \mathrm{cm}^{2}$ & 215,713 & 221,495 & 214,139 & 213,259 & 214,412 \\
\hline Maximum allowable tensile stress, $\sigma_{c c}$ & $\mathrm{kgf} / \mathrm{cm}^{2}$ & 52.59 & 45.17 & 36.34 & 54.88 & 24.13 \\
\hline
\end{tabular}

Table 2 Material properties of discontinuous fibers for FRC $[2,10]$

\begin{tabular}{|l|c|c|c|c|c|c|}
\hline Fiber: & Units & E-Glass & Basalt & Steel & PVA & PP \\
\hline Tensile strength, $\sigma_{f u}$ & $\mathrm{MPa}$ & 2500 & 3000 & 2000 & 1240 & 700 \\
\hline Modulus elasticity along the loading, $E_{f l}$ & $\mathrm{GPa}$ & 76 & 86 & 200 & 32.5 & 12 \\
\hline Modulus elasticity $\perp$ the loading, $E_{f 2}$ & $\mathrm{GPa}$ & 76 & 86 & 200 & 32.5 & 12 \\
\hline Fiber-cement: & & & & & & \\
\hline Volume fraction of fiber, $V_{f}$ & $\%$ & 0.50 & 0.50 & 0.50 & 0.75 & 1,00 \\
\hline Volume fraction of mortar, $V_{m}$ & $\%$ & 99.50 & 99.50 & 99.50 & 99.25 & 99.00 \\
\hline Modulus elasticity along the loading, $E_{c l}$ & $\mathrm{GPa}$ & 21.06 & 21.11 & 21.68 & 20.87 & 20.70 \\
\hline Modulus elasticity $\perp$ the loading, $E_{c 2}$ & $\mathrm{GPa}$ & 20.86 & 20.86 & 20.88 & 20.84 & 20.63 \\
\hline Modulus elasticity of fiber composite, $E_{c}$ & $\mathrm{kgf} / \mathrm{cm}^{2}$ & 213,669 & 213,941 & 216,920 & 212,611 & 210,658 \\
\hline $\begin{array}{l}\text { Maximum allowable tensile stress at first } \\
\text { cracking of matrix, } \sigma_{c c}\end{array}$ & $\mathrm{kgf} / \mathrm{cm}^{2}$ & 13.38 & 13.41 & 13.77 & 13.26 & 13.15 \\
\hline $\begin{array}{l}\text { Maximum allowable tensile stress at post } \\
\text { cracking of matrix, } \sigma_{p c}\end{array}$ & $\mathrm{kgf} / \mathrm{cm}^{2}$ & 31.86 & 38.23 & 25.48 & 23.70 & 17.84 \\
\hline
\end{tabular}

\section{Input Motions}

Similar with previous shaking table test, JMA Kobe $\pm 175 \mathrm{~mm} 100 \%(0.876 \mathrm{~g}) \quad$ earthquake record is used as input motions for this analysis. JMA Kobe $\pm 87.5 \mathrm{~mm}$ $(2 \mathrm{~g})$ earthquake record that is a disastrous earthquake is also used in Fig. 8.

\section{Global Analysis of Masonry House}

A global analysis is performed for the masonry structure strengthened by bandaging using fiber-cement layers on both sides of the walls. The analysis use sandwich structuresanalogy and the model can be seen in Fig. 9 .

The analysis is elastic-linear-time-history and utilizes commercial software. The strengthened masonry brickwalls consist of 3 layers: $2 \mathrm{~cm}$ fiber-cement, brick-wall, and $2 \mathrm{~cm}$ fiber-cement. It must be emphasized that in an elastic design, the damages by previous earthquakes cannot be taken into consideration because all the analysis for different levels of earthquake intensity is started from the intact building condition. In non-linear analysis, previous damages can be taken into consideration, meaning the analysis can be sequential

\subsection{Global Analysis of Masonry House with TRC}

In TRC, fiber-cement layer is a composite of mortar and one layer of fiber-mesh. The analysis results below are for 5 different meshes used in each analysis. First, maximum tensile stress occurred in brick-wall can be seen in Fig. 10. Maximum tensile stresses due to JMA Kobe 100\% are almost $0.4 \mathrm{kgf} / \mathrm{cm}^{2}$, while stresses due to JMA Kobe $2 \mathrm{~g}$ are around $0.75 \mathrm{kgf} / \mathrm{cm}^{2}$. Since the maximum allowable tensile stress of brick-wall is $3.5 \mathrm{kgf} / \mathrm{cm}^{2}$, all the results are still below the limit. This indicates the strength of the brick-walls can withstand JMA Kobe 100\% and JMA Kobe $2 \mathrm{~g}$ earthquakes after bandaged with fiber-cement layer on both sides of the wall.

Second, as a sandwich structure, there are two layers of fiber-cement which is at the inner and outer side of the brick-wall. Overall, those layers give similar maximum tensile stress results as shown in Fig. 11 and Fig. 12. Even though the outer fiber-cement layer seems to have slightly higher tensile stress than inner fiber-cement layer due to 
JMA Kobe $100 \%$, the results are still under the maximum allowable tensile stress $\left(\sigma_{c c}\right)$ calculated in Table 1.Thus, from the analysis for 5 different meshes, fiber-cement layer on both sides of the brick-wall did not crack after shaken by JMA Kobe $100 \%$. On the other hand, when using fiber glass mesh and $\mathrm{PBO}$, maximum tensile stresses occurred due to JMA Kobe $2 \mathrm{~g}$ surpass the $\sigma_{c c}$.

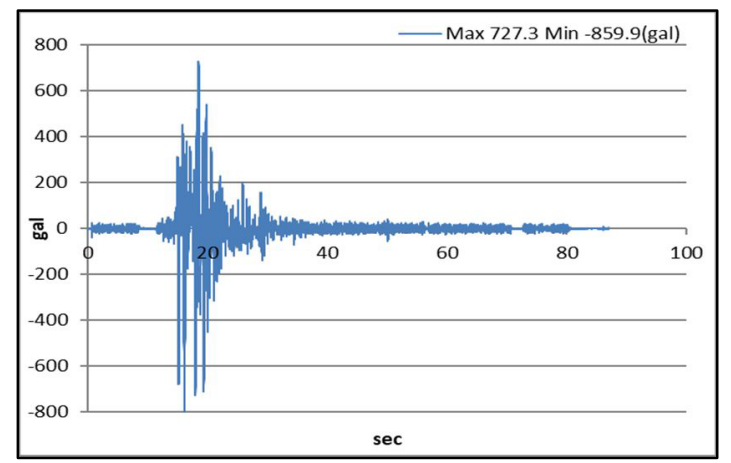

(a)

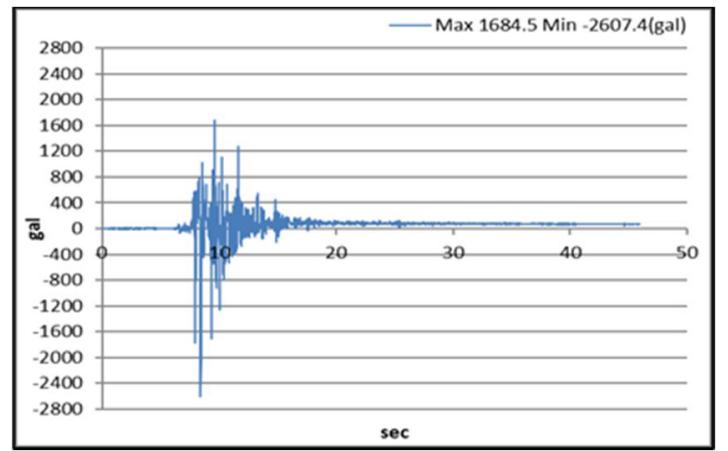

(b)

Fig. 8 Input motion of JMA Kobe NS 100\% (a) and JMA Kobe 2g (b)

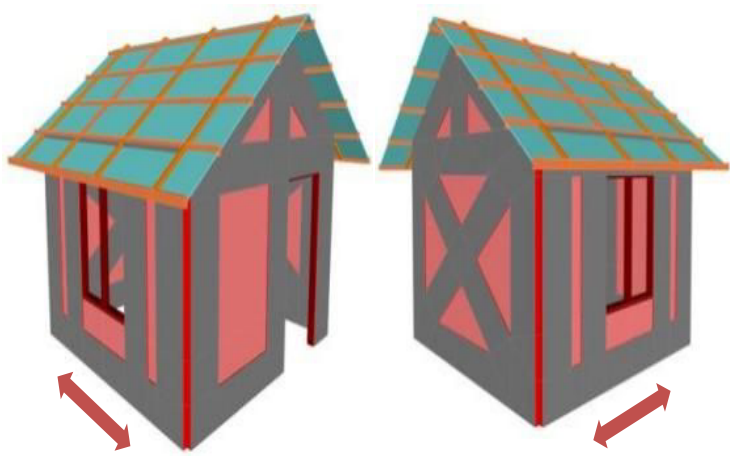

Fig. 9 Model 3D for analysis [14] [15]

The maximum allowable tensile stresses are about $40 \mathrm{kgf} / \mathrm{cm}^{2}$, while $\sigma_{c c}$ for both fiber glass mesh and PBO are $36.34 \mathrm{kgf} / \mathrm{cm}^{2}$ and $24.13 \mathrm{kgf} / \mathrm{cm}^{2}$ respectively as mentioned in Table 1. Tensile stress of PBO is the highest among the other fibers, namely $3,356 \mathrm{MPa}$. However, since the volume fraction is very small $(0.14 \%)$, the $\sigma_{c c}$ as fibercement layer is the lowest. For this reason, the fibercement layer might crack in certain areas but will not cause collapse of the overall structure. As for three other fibers used in the analysis, namely basalt, carbon, and aragrid, all the $\sigma_{c c}$ are higher as can be seen in Table 1. Therefore, those fiber-cement layers are stronger and can withstand JMA Kobe $2 \mathrm{~g}$.

Third, to give better clarification of the analysis results, Fig. 13 to Fig. 15 represent one of the tensile stress patterns of both brick-wall and fiber-cement layer for fiber glass mesh. The patterns are taken at certain time when maximum tensile stresses occurred in the structure. For easy reading, for low and high tensile stress that occurred in the structure, color indicators are plotted on the right side; bottom line (pink color) meaning $0 \mathrm{kgf} / \mathrm{cm}^{2}$; upper part indicates the maximum allowable tensile stress (blue color). Therefore, if the color in the structure is blue, the stress exceeds the limit, hence indicating possibility of crack in the structure.

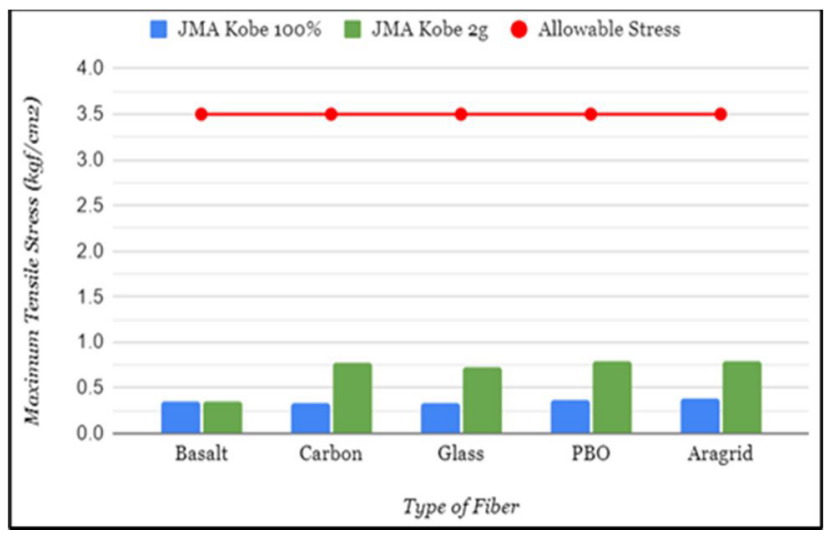

Fig. 10. The maximum tensile stress of brick-wall

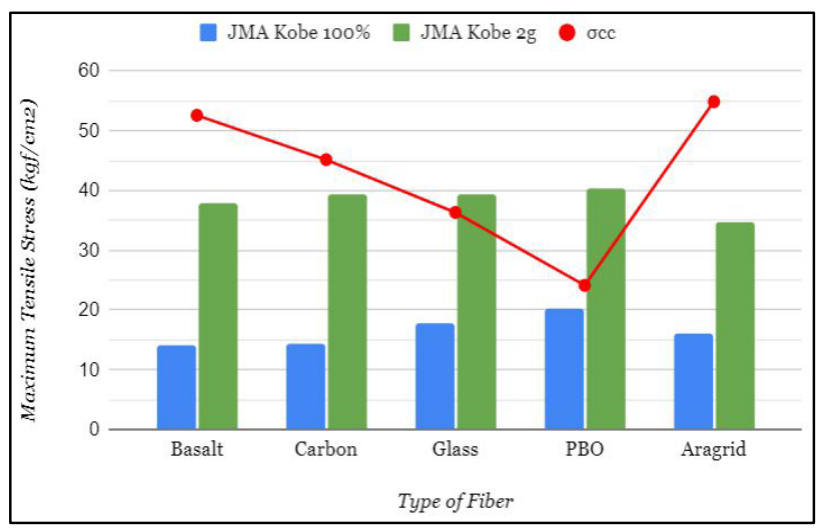

Fig. 11. The maximum tensile stress of the outer fiber-cement layer

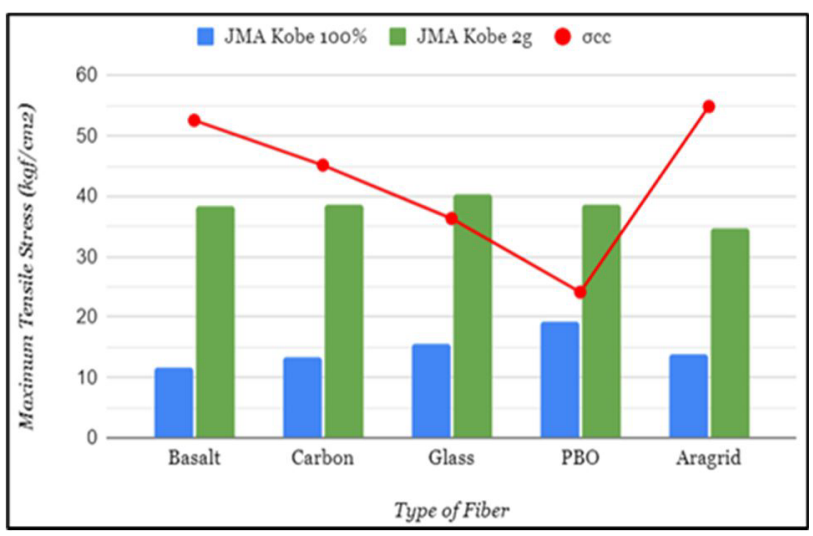

Fig. 12 Maximum tensile stress of the inner fiber-cement layer 


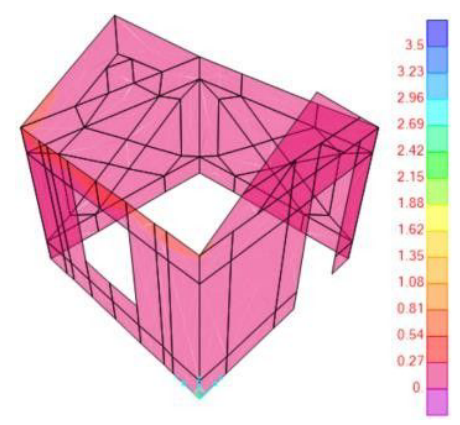

(a)

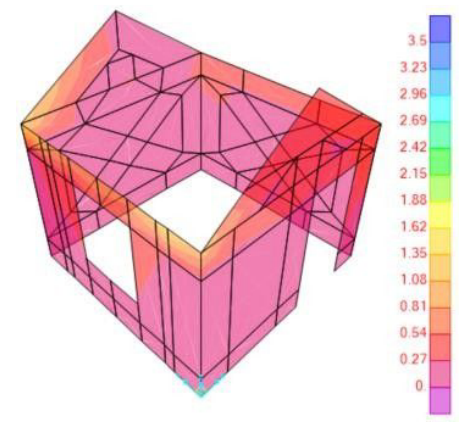

(b)

Fig. 13. Maximum tensile stress pattern $\left(\mathrm{kgf} / \mathrm{cm}^{2}\right)$ of brickwalls due to JMA Kobe $100 \%$ (a) and JMA Kobe $2 \mathrm{~g}$ (b) using Fiber Glass Mesh

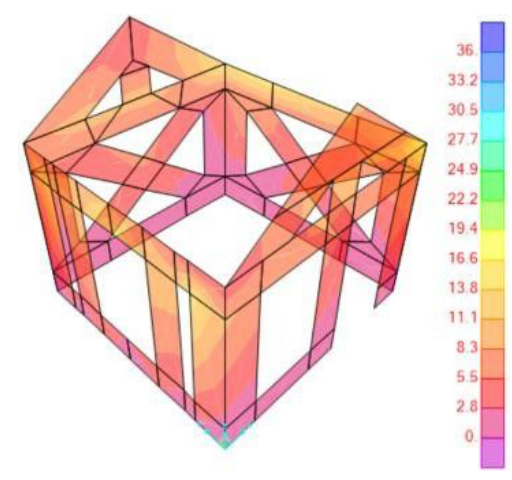

(a)

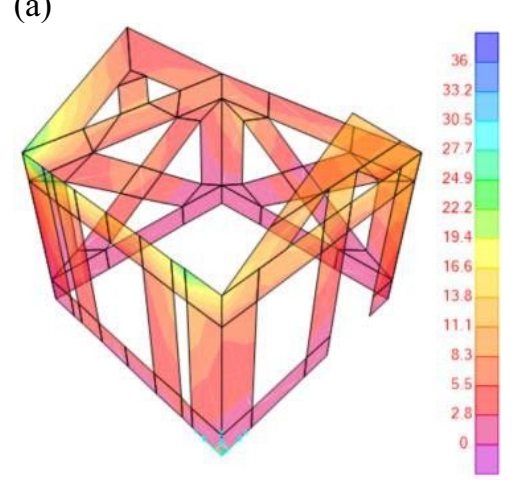

(b)

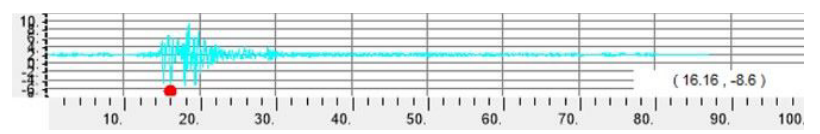

Fig. 14. Maximum tensile stress pattern $\left(\mathrm{kgf} / \mathrm{cm}^{2}\right)$ at 16.16s ofinner (a) and outer (b) fiber-cement layers using Fiber Glass Mesh due to JMA Kobe 100\%

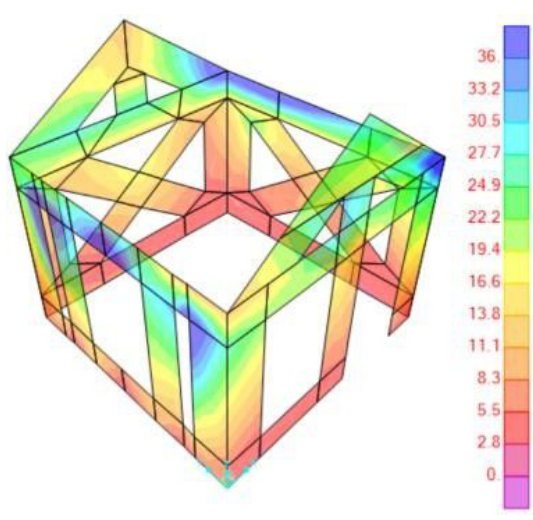

(a)

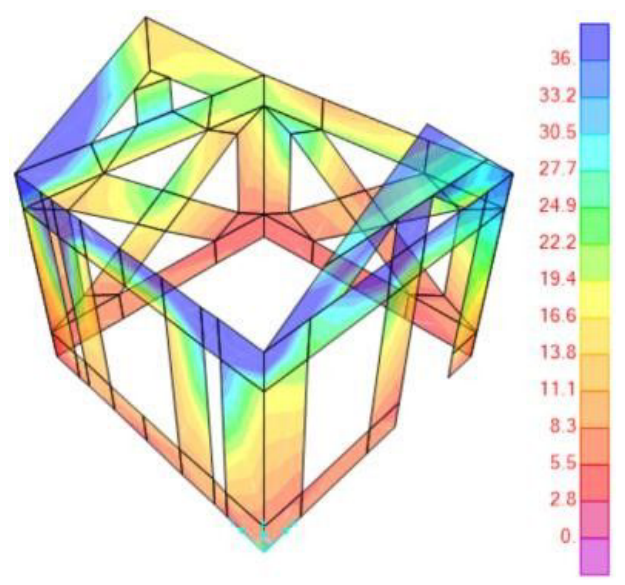

(b)

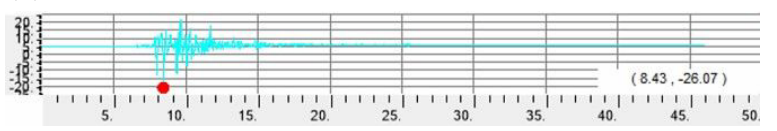

Fig. 15. Maximum tensile stress pattern $\left(\mathrm{kgf} / \mathrm{cm}^{2}\right)$ at $8.43 \mathrm{~s}$ of inner (a) and outer (b) fiber-cement layers using Fiber Glass Mesh dueto JMA Kobe $2 \mathrm{~g}$

\subsection{Global Analysis of Masonry House with FRC}

The fiber-cement layer is a composite of mortar and discontinuous fibers. Fig. 16 and Fig. 17 show the maximum tensile stress in fiber-cement due to JMA Kobe $100 \%(0.876 \mathrm{~g})$ and JMA Kobe $2 \mathrm{~g}$ for five different discontinuous fibers as shown in Table 2. Since the volume fraction of fibers are relatively small (below 1\%), no matter what fiber is used, the matrix (mortar) tensile strength plays an important role as a limit where the first crack in mortar occurs [2]. All tensile stresses are below the tensile stress at first cracking of the matrix, indicating there is no crack in any FRC bandage (see Fig. 16 and Fig. 17). The masonry house bandaged with FRC can survive when shaken by JMA Kobe $100 \%(0.876 \mathrm{~g})$.

When progressive cracks occur, the load will be transferred from matrix to the embedded fibers, and finally when the matrix is fully cracked, the load is mainly sustained by the fiber $[2,13,16]$. For FRC with high tensile strength and high modulus elasticity (E-glass fiber, basalt fiber, and steel fiber), the maximum tensile stress did not exceed the maximum post cracking stress $(\sigma p c)$, meaning when shaken by JMA Kobe $2 \mathrm{~g}$, substantial cracks may start to develop in the FRC walls, but the fibers are intact. For FRC with low tensile strength and low modulus 
elasticity (PVA fiber and PP fiber), it seems that some of fibers in fiber-cement might be failed at several places, but not for the overall structure since Fig. 16 and Fig. 17 only show the maximum value that can occur for the overall structure at one-time (the highest stress).

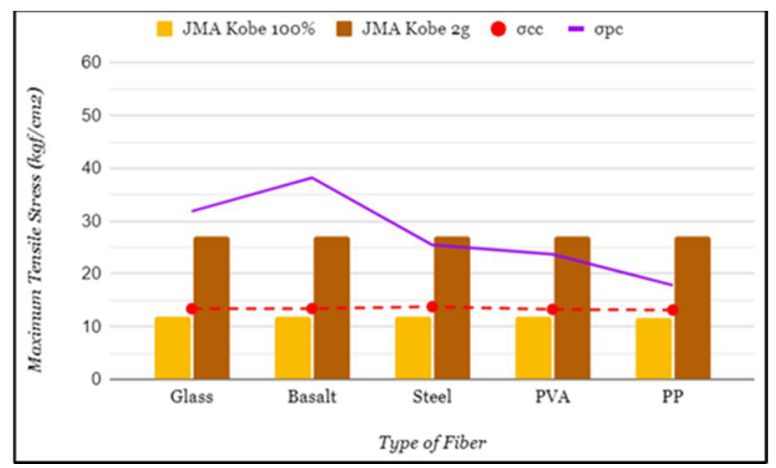

Fig. 16 Maximum tensile stress in fiber-cement of masonry wallbandaged with FRC due to JMA Kobe $100 \%(0.876 \mathrm{~g})$

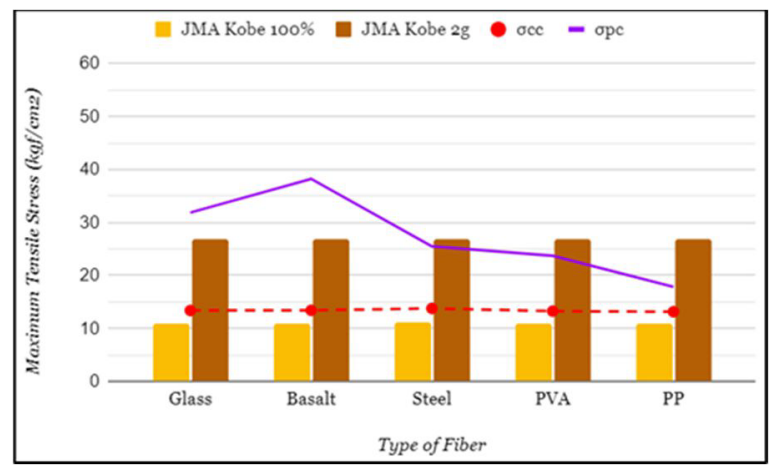

Fig. 17 Maximum tensile stress in fiber-cement of masonry wall bandaged with FRC due to JMA Kobe 2

The maximum tensile stress of brick-wall due to JMA Kobe $100 \%$ and JMA Kobe $2 \mathrm{~g}$ is below the limit $\left(3.5 \mathrm{kgf} / \mathrm{cm}^{2}\right)$ for all masonry houses bandaged with FRC with 5 different types of fiber in Fig. 18. Since all the brickwall stresses are below the limit, it is a clear indication that fiber-cement layers (FRC) can be used similar with ferrocement layers in strengthening existing buildings as well as retrofitting earthquake damaged buildings

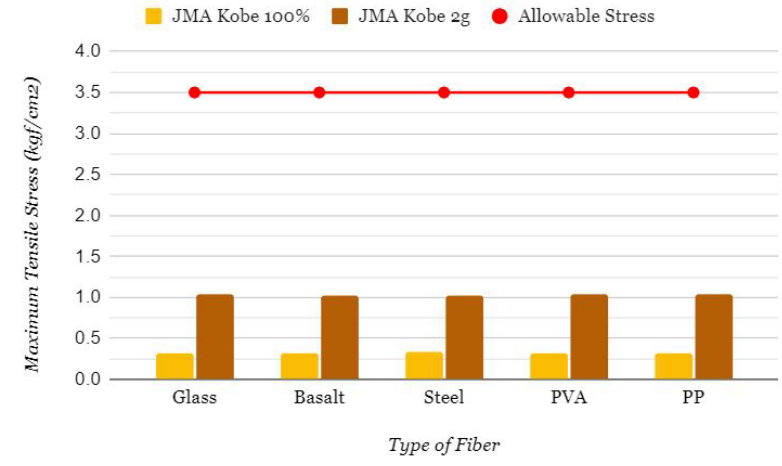

Fig. 18 Maximum tensile stress in fiber-cement of masonry wall bandaged with FRC due to JMA Kobe 2

Fig. 19 to Fig. 21 show the tensile stress patterns of FRC with E-glass fiber to give an idea what can happen in FRC layers when shaken by earthquakes. The stress patterns for basalt fiber and steel fiber are similar with that of E-glass fiber. Meanwhile, Fig. 23 to Fig. 25 show the tensile stress pattern of FRC with PP fiber that represent the low-end synthetic fibers. To improve the performance of FRC with low-end fiber, the volume fraction of fiber can be increased around $1.5 \%$, however, it might not be necessary since earthquake with $2 \mathrm{~g}$ magnitude most probably will not occur in the lifetime of common people's housing.

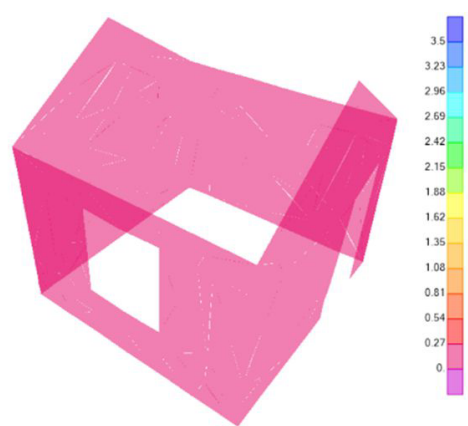

(a)

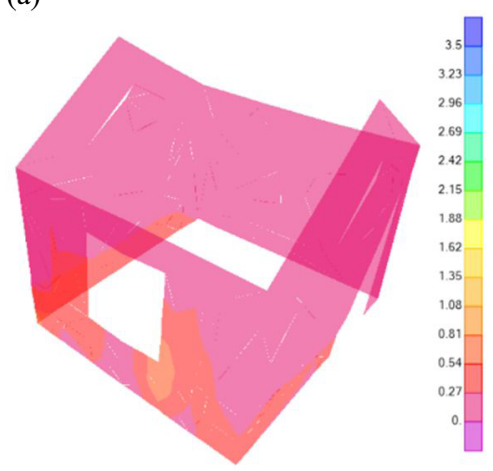

(b)

Fig. 1 Maximum tensile stress pattern $(\mathrm{kgf} / \mathrm{cm} 2)$ of brick-walls due to JMA Kobe $100 \%$ (a) and JMA Kobe $2 \mathrm{~g}$ (b) using E-Glass Fiber
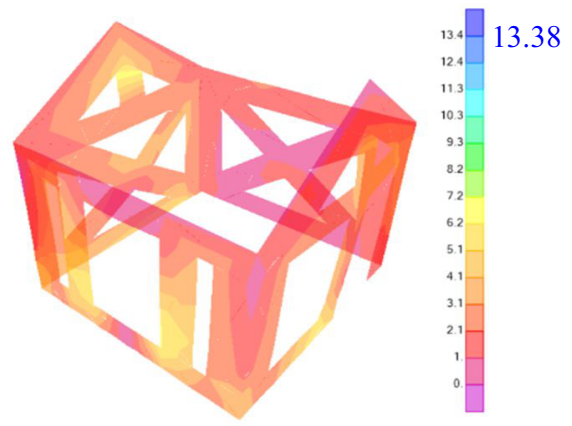

(a)

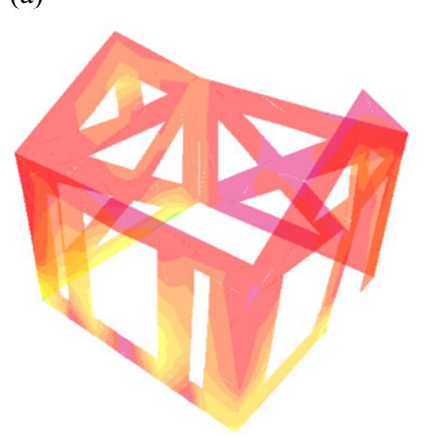

13.38

(b)

Fig. 2 Maximum tensile stress pattern $\left(\mathrm{kgf} / \mathrm{cm}^{2}\right)$ of inner (a) and outer (b) fiber-cement layers using E-Glass Fiber due to JMA Kobe $100 \%$; the tensile stresses are below the first cracking of matrix, $\sigma_{c c}$ 


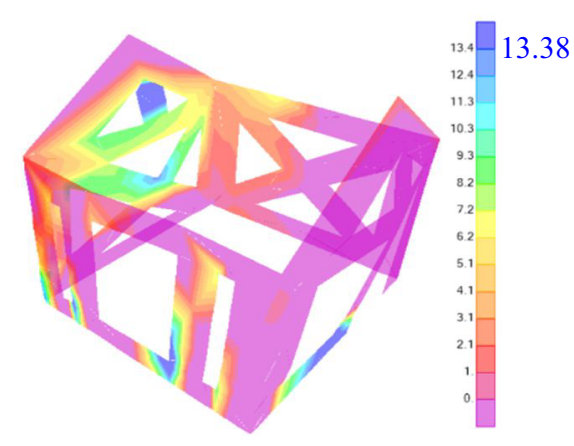

(a)

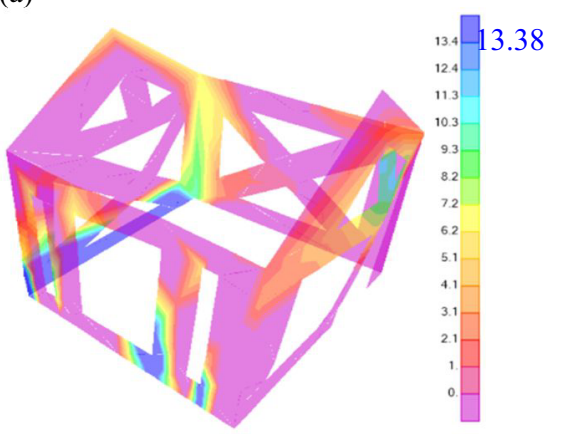

(b)

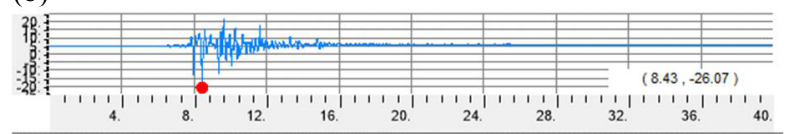

Fig. 3 Tensile stress pattern $\left(\mathrm{kgf} / \mathrm{cm}^{2}\right)$ at $8.43 \mathrm{~s}$ of inner (a) and outer (b) fiber-cement layers using E-Glass Fiber due to JMA Kobe $2 \mathrm{~g}$.

Blue color ( $\square$ ) indicates tensile stres $4 \mathrm{~s}$ exceeded the tensile stress at first cracking of matrix, meaning substantial cracks start to develop in walls; however, the fiber did not fail because the stress still below the maximum post-cracking stress $31.86 \mathrm{kgf} / \mathrm{cm}^{2}$, as can be seen in Fig. 4.

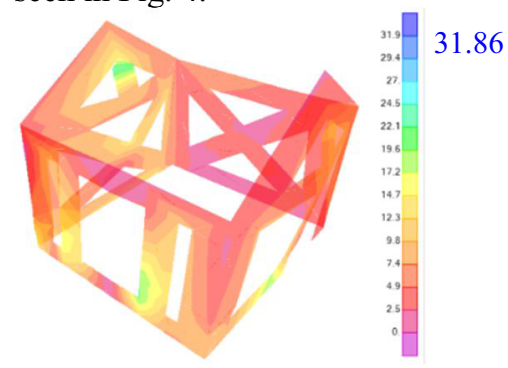

(a)

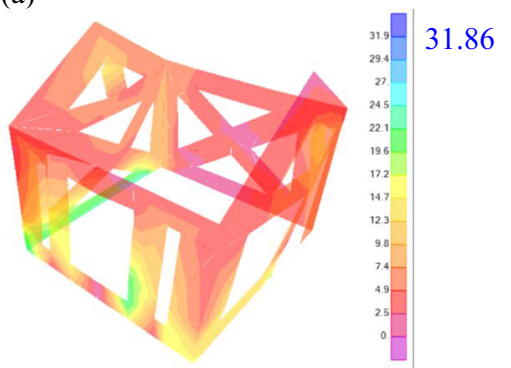

(b)

Fig. 4 Maximum tensile stress pattern $\left(\mathrm{kgf} / \mathrm{cm}^{2}\right)$ of inner (a) and outer (b) fiber-cement layers using E-Glass Fiber due to JMA Kobe $2 \mathrm{~g}$; the tensile stresses are below the post cracking of matrix, $\sigma_{p c}$
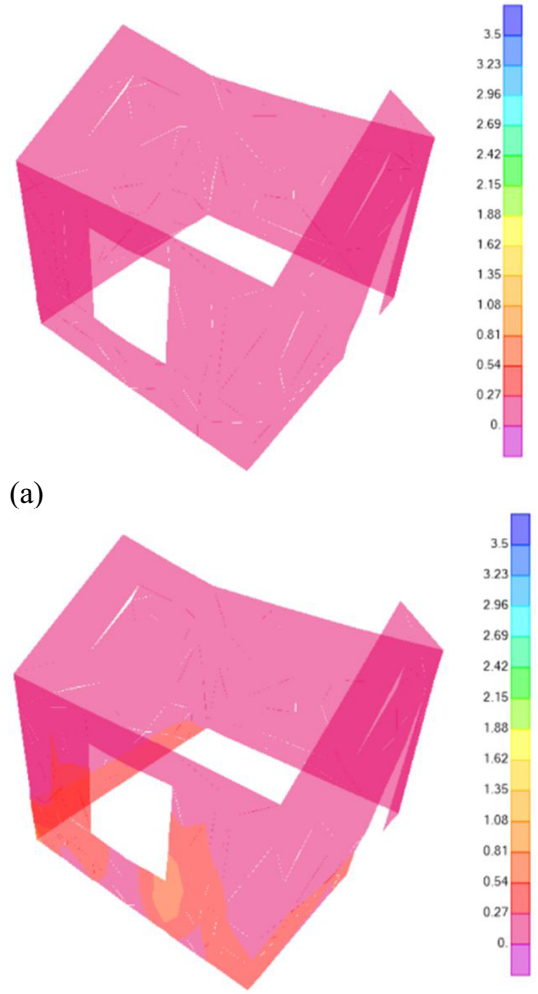

(b)

Fig. 5 Maximum tensile stress pattern $\left(\mathrm{kgf} / \mathrm{cm}^{2}\right)$ of brick-walls due to JMA Kobe $100 \%$ (a) and JMA Kobe $2 \mathrm{~g}$ (b) using PP Fiber
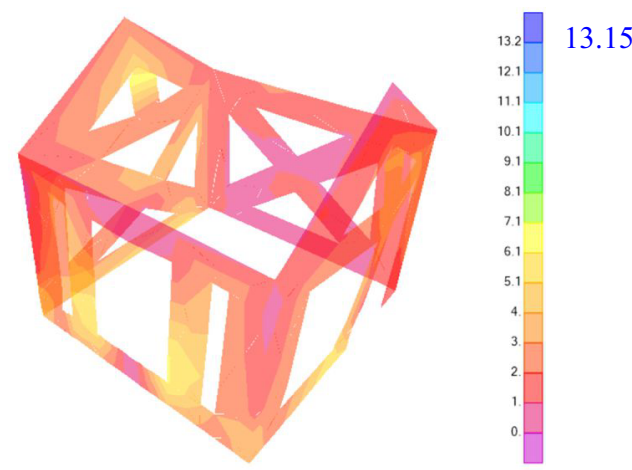

(a)
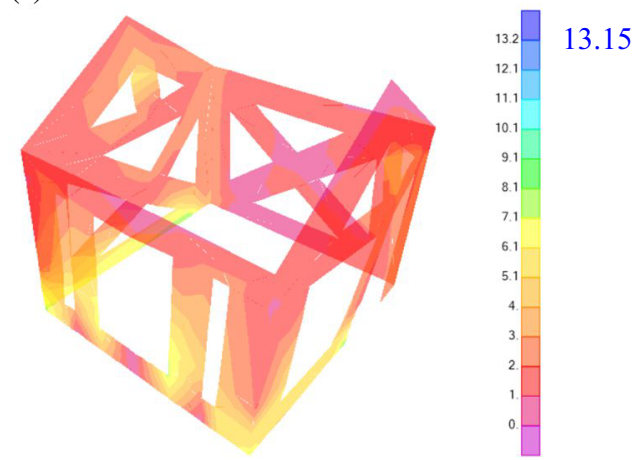

(b)

Fig. 6 Maximum tensile stress pattern $\left(\mathrm{kgf} / \mathrm{cm}^{2}\right)$ of inner (a) and outer (b) fiber-cement layers using PP Fiber due to JMA Kobe $100 \%$; the tensile stresses are below the first cracking of matrix, $\sigma_{c c}$ 

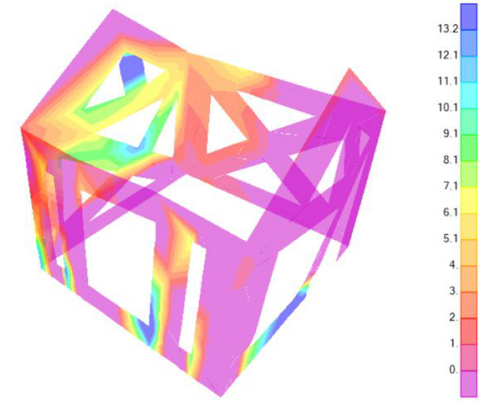

13.15

(a)

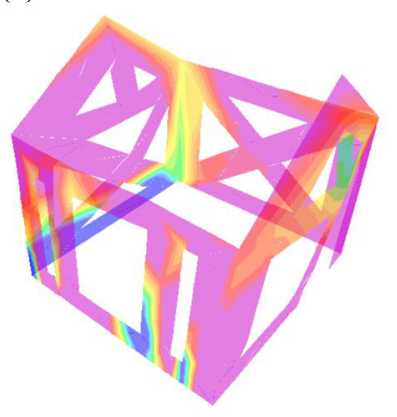

(b)

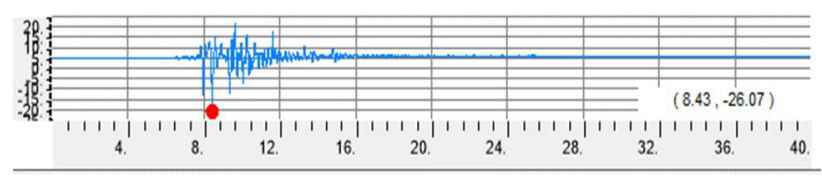

Fig. 7 Tensile stress pattern $\left(\mathrm{kgf} / \mathrm{cm}^{2}\right)$ at $8.43 \mathrm{~s}$ of inner (a) and outer (b) fiber-cement layers using PP Fiber due to JMA Kobe $2 \mathrm{~g}$

Blue color ( $\square$ ) indicates tensile stress exceeded the tensile stress at first cracking of matrix, meaning substantial cracks start to develop in walls; some of PP fibers might be pulled out simultaneously since the stress exceeded the post-cracking stress $17.84 \mathrm{kgf} / \mathrm{cm}^{2}$ as can be seen in Fig. 8
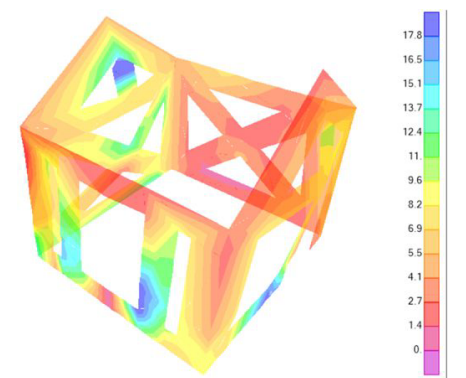

17.84

(a)
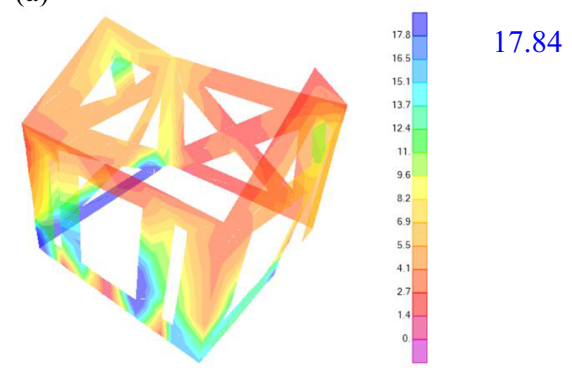

(b)

Fig. 8 Maximum tensile stress pattern $\left(\mathrm{kgf} / \mathrm{cm}^{2}\right)$ of inner (a) and outer (b) fiber-cement layers using PP Fiber due to JMA Kobe $2 \mathrm{~g}$

\section{Cementitious Matrix Mix}

The mortar for TRC is 1 cement:4sand. However, for FRC, it needs extra handling when adding the fiber to the mortar mix. The mortar should be produced first to its desired consistency, then add the fibers gradually and make sure they disperse well. The addition of fibers tends to decrease fluidity and workability; therefore, it may be necessary to hold part of the water and only add them in steps during fiber addition. After all fibers are added, the mortar mix should be mixed for 2-3 minutes. The mix of dry cement or dry sand with fibers should be avoided because it can be damaging the fibers. The fibers tend to break under the impact of mixer and the pounding of aggregates.

Problems during mixing can occur if the volume fraction of fibers used is high. The fibers cannot disperse well and forming as solid ball within the mixture. The fibers are segregating from the mix and lead to balling. If the mortar mixing procedure is well followed, the problem should not occur because the volume fraction of fibers used is small, only $0.5 \%-1 \%$.

\section{Conclusion}

The purpose of the analysis is not to simulate the actual behavior, but to get reliable information that there is a correlation between the observed damages and the results of the analysis. The correlation is not perfect but is good enough to get an idea on how to build appropriate non-engineered constructions that can withstand earthquakes. Based on the authors' judgement, the analysis results provide justification for constructing earthquake resistant masonry houses as well as retrofitting existing masonry houses bandaged with TRC and FRC.

The type of fibers, the dimensions and shape of fibers (the yarns, yarn spacing, and direction), the presence of yarn coating or impregnation and weaving technique affect the matrix-fiber interaction and influence a specific behavior and properties of TRC system. Therefore, the fiber-mesh should be chosen carefully. In Indonesia, what fibers to be used are not yet decided. However, whatever fiber available with material properties similar to the five fibers analyzed, can safely be used. Another method to verify the results is a fullscale shaking table test which hopefully can be conducted in the near future.

\section{References:}

1. T. Boen, H. Imai, F. Ismail, T. Hanazato and Lenny, "Brief Report of Shaking Table Test on Masonry Building Strengthened with Ferrocement Layers," Journal of Disaster Research, 10, 551-557 (2015)

2. A. E. Naaman, Fiber Reinforced Cement and Concrete Composite, Sarasota: Techno Press 3000 (2018) 
3. A. E. Naaman, Ferrocement \& Laminated Cementitious Composites, Michigan: Techno Press 3000 (2000)

4. H. Imai and A. Nakatani, "Seismic Reinforcement of Masonry Construction Experiment: Shaking Table Experiments on Full Scale Masonry Walls using Bricks made in Padang, Indonesia," National research Institute for Earth science and Disaster prevention (NIED) \& Mie University, Tsukuba, Japan (2012)

5. A. E. Naaman, "Evolution in Ferrocement and Thin Reinforced Cementitious Composites," Arab Journal Science Engineering, 421-441, (2012)

6. ACI Committee 549.6R-20, Guide to Design and Construction of Externally Bonded FabricReinforced Cementitious Matrix (FRCM) and Steel-Reinforced Grout (SRG) Systems for Repair and Strengthening Masonry Structures, Farmington Hills, MI: American Concrete Institute (2020)

7. G. de Felice,. T. D'Antino, S. de Santis, P. Meriggi and F. Roscini, "Lessons Learned on the Tensile and Bond Behavior of Fabric Reinforced Cementitious Matrix (FRCM) Composites," Frontiers in Built Environment, 6, 5, 1-15 (2020)

8. T. Triantafillou, Textile Fibre Composites in Civil Engineering, Elsevier (2016)

9. M. Aziz, P. Paramasivam and S. Lee, "Natural Fibre Reinforces Concretes in Low-Cost Housing Construction," Journal of Ferrocement, 17, 3, 231-240 (1987)

10. Wikipedia, "Basalt Fiber," 29 January 2021. [Online]. Available: https://en.wikipedia.org/wiki/Basalt_fiber. [Accessed 2 May 2021].
11. U. N. Gandhi, S. Goris, T. A. Osswald and Y.-Y. Song, Discontinuous Fiber-Reinforced Composites - Fundamentals and Applications, Munich: Carl Hanser Verlag (2020)

12. Cambridge University Pers, "https://in.bgu.ac.il/," 1996. [Online]. Available: https://in.bgu.ac.il/engn/mater/Documents/Labor atoryBriefings/4/Materials $\% 20$ Science $\% 20$ and $\%$ 20Engineering\%20introduction $\% 20$ Chapter $\%$ 2015\%20Composites\%207th\%20ed.pdf. [Accessed 5 May 2021].

13. A. E. Naaman, "High Performance Fiber Reinforced Cement Composites: Classifications and Applications," in CBM-CI International Workshop, Karachi, Pakistan, November 9-11, (2007)

14. Software, "ETABS v.19 Computers \& Structures Inc.," Walnut Creek, California, United States of America (2021)

15. Software, "SAP2000 v.23 Computers \& Structures Inc.," Walnut Creek, California, United States of America (2021)

16. M. Leone, M. A. Aiello, A. Balsamo, F. G. Carozzi, F. Ceroni, M. Corradi, M. Gams, E. Garbin, N. Gattesco, P. Krajewski, C. Mazzotti, D. Oliveira, C. Papanicolaou, G. Ranocchiai, F. Roscini and D. Saenger, "Glass fabric reinforced cementitious matrix: Tensile properties and bond performance on masonry substrate," Composites Part B - Elsevier, 196-214 (2017)

17. P. K. V. R. Padalu, Y. Singha and S. Das, "Tensile properties of wire and fibre reinforced cementitious matrix composites for strengthening of masonry," Structures Elsevier, 23,164-179 (2020) 